MEYER, Brigitte, Neuruppin 1700 bis 1830.

Sozialgeschichte einer kurmärkischen Handwerker- und Garnisonsstadt

\title{
Étienne François
}

\section{OpenEdition}

1 Journals

Édition électronique

URL : http://journals.openedition.org/ifha/1995

DOI : $10.4000 /$ ifha. 1995

ISSN : 2198-8943

Éditeur

IFRA - Institut franco-allemand (sciences historiques et sociales)

Référence électronique

Étienne François, « MEYER, Brigitte, Neuruppin 1700 bis 1830. Sozialgeschichte einer kurmärkischen Handwerker- und Garnisonsstadt », Revue de l'IFHA [En ligne], Date de recension, mis en ligne le 01 janvier 1994, consulté le 22 septembre 2020. URL : http://journals.openedition.org/ifha/1995 ; DOI : https://doi.org/10.4000/ifha.1995

Ce document a été généré automatiquement le 22 septembre 2020.

(C)IFHA 


\title{
MEYER, Brigitte, Neuruppin 1700 bis 1830. Sozialgeschichte einer kurmärkischen Handwerker- und Garnisonsstadt
}

\author{
Étienne François
}

Sur une petite ville du Brandebourg ( 3500 habitants au début du règne de Frédéric II, 4 000 après sa mort), connue avant tout pour sa proximité du château de Rheinsberg, pour avoir donné naissance à Schinkel et à Fontane, puis pour avoir été le lieu de production de millions de gravures imprimées en couleur (les »Neuruppiner Bilderbögen« qui sont l'équivalent prussien des images d'Epinal), une étude d'histoire démographique et sociale issue d'une thèse dirigée par Helga Schultz (et s'inspirant très directement de son enquête sur Berlin entre 1650 et 1800), soutenue en 1988 à l'Académie des Sciences de Berlin-Est, et complétée (en particulier dans sa bibliographie et ses comparaisons) grâce aux nouvelles opportunités offertes par la Wende. Reposant sur un dépouillement systématique des registres paroissiaux et des archives locales, appuyée sur 35 tableaux statistiques et 11 graphiques, cette enquête minutieuse et érudite propose une reconstitution utile par sa précision d'une "ville sans qualités«. Trois aspects paraissent plus particulièrement intéressants: l'originalité d'abord d'une conjoncture urbaine en rupture avec l'histoire politique, puisque les belles années de Neuruppin sont d'une part le premier tiers du XVIIIe s., et de l'autre l'extrême fin du siècle et le début du XIXe s., alors que le règne du grand Frédéric correspond à une phase de stagnation, voire de crise; la remarquable stabilité ensuite de structures sociales dominées par le monde de l'artisanat (avant tout du textile) et fidèles jusqu'à la fin de la période d'observation à une »démographie d'ancien régime«; la multiplication enfin à partir du dernier tiers du XVIIIe s. dans le monde de la petite et de la moyenne bourgeoisie d'initiatives et d'innovations ouvrant la voie à une modernisation par la base sans éclat mais efficace, stimulée par la reconstruction de la ville après le grand incendie de 1787, puis les réformes du début du XIXe s. Un seul regret: la place trop restreinte faite par cette étude à la prise en compte des réalités 
militaires dans la ville où le rôle de l'armée et de la garnison est manifestement si essentiel.

2 Étienne FRANÇOIS 